\title{
Nintendo related injuries and other problems: review
}

\author{
(ब) $(\mathbb{Q} \Theta$ OPEN ACCESS
}

\author{
Maarten B Jalink medical doctor ${ }^{1}$, Erik Heineman professor, paediatric surgeon ${ }^{1}$, Jean-Pierre E N \\ Pierie professor, general surgeon ${ }^{23}$, Henk O ten Cate Hoedemaker abdominal surgeon ${ }^{12}$
}

${ }^{1}$ Department of Surgery, University of Groningen, University Medical Centre Groningen, Groningen, 9700 RB Groningen, Netherlands; ${ }^{2}$ Postgraduate School of Medicine, University Medical Center Groningen, Groningen, Netherlands; ${ }^{3}$ Department of Surgery, Medical Centre Leeuwarden, Leeuwarden, Netherlands

\begin{abstract}
Objective To identify all reported cases of injury and other problems caused by using a Nintendo video gaming system.

Design Review.

Data sources and review methods Search of PubMed and Embase in June 2014 for reports on injuries and other problems caused by using a Nintendo gaming system.

Results Most of the 38 articles identified were case reports or case series. Injuries and problems ranged from neurological and psychological to surgical. Traditional controllers with buttons were associated with tendinitis of the extensor of the thumb. The joystick on the Nintendo 64 controller was linked to palmar ulceration. The motion sensitive Wii remote was associated with musculoskeletal problems and various traumas.
\end{abstract}

Conclusions Most problems are mild and prevalence is low. The described injuries were related to the way the games are controlled, which varies according to the video game console.

\section{Introduction}

Nintendo was founded in 1889 by Fusajiro Yamauchi in Kyoto, Japan. ${ }^{1}$ The company originally sold Japanese playing cards, but after the second world war it experimented with products such as toys, hotels, and taxi services. In the late 1970s, Nintendo started selling video game systems. With its success in Japanese and Western markets, the company grew to become the multinational that entertains so many people today. Its latest big hit, the Wii console, has sold more than 100 million units. ${ }^{2}$ Because of its popularity, Nintendo's consoles and handheld units are common Christmas presents.

Nintendo's innovative products are also increasingly used for healthcare. The pressure sensitive balance board, which assesses balance ability, ${ }^{3}$ can train balance in older people and patients with multiple sclerosis or Parkinson's disease. ${ }^{4-8}$ In addition, the motion sensitive Wii remote controller can be used to improve basic laparoscopic skills, ${ }^{9}{ }^{10}$ and so called exergames are used for exercise in children with cystic fibrosis, ${ }^{11}$ weight loss, ${ }^{12}{ }^{13}$ cardiovascular training,${ }^{14}$ and postoperative rehabilitation. ${ }^{15}$

However, there have been reports of Nintendo related injuries and other problems, which range from mild to life threatening. We therefore decided to gather all reported cases of Nintendo related problems to see whether a Nintendo is safe to give as a Christmas present.

\section{Methods}

In June 2014 we searched PubMed and Embase using the terms "Nintendo", "Game \& Watch", "Famicom", "Game Boy" (or the commonly miswritten "Gameboy"), "Virtual Boy", "iQue", "GameCube", and "Wii". Our search identified 1198 articles-543 from PubMed and 655 from Embase. After reading the titles and abstracts (if available), we selected all original papers that reported Nintendo related problems. We then screened all papers, including three reviews of Wii related injuries, ${ }^{16-18}$ for other suitable references. With the exception of one German article, all papers were written in English.

\section{Results}

We identified 38 relevant papers (30 case reports, seven case series, and one prospective study). The reports were split into two groups-before and after the introduction of the Wii (www. nintendo.co.uk). Before the Wii, Nintendo's consoles had a traditional wired controller with buttons or a joystick. Wii games, however, are controlled by a motion sensitive remote, which requires players to swing their arms, resulting in more traumatic injuries. 


\section{Early reports}

One of the first cases was that of a 13 year old girl who experienced a generalised seizure after playing Super Mario Bros on her Nintendo entertainment system (1984) for almost three hours. ${ }^{19}$ This "Nintendo epilepsy" was attributed to a rapid change of on-screen patterns. A large multicentre study later showed that patients with a history of seizures when watching television were more sensitive to a game similar to Super Mario Bros than to a normal television programme. ${ }^{20}$

In the early 1990s two cases of Nintendo related incontinence were published. ${ }^{21}{ }^{22}$ One described a boy who developed episodes of faecal soiling, ${ }^{21}$ and the other reported three (related) boys who suddenly developed daytime enuresis. ${ }^{22}$ All children were so engrossed in Super Mario Bros that they ignored their urge to go to the toilet. All cases were successfully treated by explaining how to pause the game. One of the authors jokingly suggested that Nintendo should develop a wet sensor that aborts the game if a player loses bladder control. ${ }^{22}$

In 1991, an author described how his son developed intense neck pain after playing his Game Boy-a portable system first marketed in 1989 with a small unlit display-for 30 minutes. ${ }^{23}$ His position while playing was reported as "hunched over, chin almost resting on his chest, elbows bent while he holds the small screen close to his face." The boy's problems, dubbed "Nintendo neck," were attributed to playing in this position.

Similarly, "Nintendo elbow" was diagnosed in a 12 year old boy who had pain in his right elbow after playing his Nintendo "a lot" for more than a month. ${ }^{24}$ Symptoms resolved with non-steroidal anti-inflammatory drugs and rest.

We also found a report of "Nintendo hallucinations." The patient, who had previously been diagnosed as having paranoid schizophrenia, had persistent auditory hallucinations of video game music. $^{25}$

\section{Nintendinitis}

Nintendo related problems in the thumb, hand, and wrist are referred to as "nintendinitis" or "nintendonitis." All reports, mostly letters to the editor, point out that strenuous game play with a traditional controller can result in temporary discomfort, most commonly as a result of tendinitis of the extensor pollicis longus, and can be treated by rest or non-steroidal anti-inflammatory drugs (or both).

The first case dates back to 1990 . The patient was a 35 year old woman who experienced severe pain in her right thumb after playing her Nintendo uninterrupted for five hours. ${ }^{26}$ A similar case, which was termed nintendinitis - a form of tendinitis — was caused by repetitive microtrauma. ${ }^{27}$ The authors of similar case reports suggested that prophylactic hand care instructions should be given at school. ${ }^{28}{ }^{29}$ Another report described a boy who developed eczema on both his thumbs after playing his Game Boy on a daily basis. ${ }^{30}$

After the introduction of the Nintendo 64 console in 1997, reports of the original nintendinitis subsided. But with a new controller, new problems arose. The Nintendo 64 was Nintendo's first console that featured three dimensional graphics. ${ }^{1}$ Its controller featured a joystick that made three dimensional navigation easier but also gave rise to ulcerative nintendinitis-a central palmar ulcer. ${ }^{31}{ }^{32}$ In some games, Mario Party in particular, players had to rotate the joystick quickly with their thumb. Players discovered that it was quicker to rub the joystick with their palm, but this resulted in ulceration. After receiving more than 90 complaints, Nintendo handed out protective gloves to all owners of the game, which had already sold a million copies. $^{33}$

\section{Enter the Wii}

In 2006, Nintendo introduced the Wii, a console with a controller (remote) that detects motion, speed, and position. ${ }^{1}$ In its most popular game, Wii Sports, players swing these Wii remotes to participate in sports such as tennis and boxing. This resulted in new types of injury, mostly traumatic ones. In 2009, a preliminary report with data on 21 Wii related injuries from the National Electronic Injury Surveillance System showed that most injuries were confined to the upper extremities, face, and neck. ${ }^{34}$ A review of 39 Wii injuries that gamers self reported through a special website found that Wii Sports had caused the injury in 34 cases, with tennis being most commonly implicated..$^{35}$ The most common injuries were hand lacerations and bruising, as well as periorbital haematomas.

\section{"Wiiitis"}

The first Wii related injury, dubbed "wiiitis," was seen in a 29 year old man who experienced acute tendinitis of his right infraspinatus muscle after playing Wii Sports for several hours. ${ }^{36}$ Others also reported acute muscle pain in the upper extremities after playing the game. ${ }^{37}{ }^{38}$ One report even described a case of arm swelling and a rise in creatine kinase, consistent with serious muscle injury. ${ }^{39}$ Magnetic resonance imaging in another case of upper extremity wiiitis showed increased signal intensity in various muscles of the upper extremities. ${ }^{40}$ Wiiitis can affect various muscles in the arm and shoulder, depending on the movements made during different games. All cases were treated with rest and non-steroidal anti-inflammatory drugs.

As with nintendinitis, the term wiiitis is used for various injuries. In 2010, four paediatric cases of wiiitis were reported; children presented not only with a painful arm, but also with a painful neck and postural deviations. ${ }^{41}$ Another report described a case of carpal tunnel syndrome in a woman who played a bowling game for six to eight hours daily for 10 days. ${ }^{42}$ There are also two reports of Achilles wiiitis-a (partial) tear of the Achilles tendon. ${ }^{434}$ In addition, one case of wiiitis presented as a massive venous thrombosis of the gluteal veins that reached as far as the inferior vena cava. ${ }^{45}$

\section{Wii knee}

The term "Wii knee" encompasses all Wii related knee injuries. The first report was of a young woman who dislocated her left patella when she fell while serving a tennis ball in Wii Sports. ${ }^{46}$ In addition, a boy who twisted his knee while playing the Wii dislocated his patella and fractured his lateral femoral condyle, ${ }^{47}$ and another report mentions a medial meniscal tear in a woman who was playing a bowling game. ${ }^{48}$

\section{Surgerii}

Wii related injuries can be life threatening. A 55 year old woman sustained a massive haemothorax $(>1250 \mathrm{~mL})$ after falling on her sofa while playing tennis on her Wii. ${ }^{49}$ Another patient required resection of infarcted bowel when a pre-existing paraumbilical hernia strangulated while doing exercises with Wii Fit. ${ }^{50}$ Two patients were admitted with ischaemic stroke owing to an internal carotid artery dissection after playing the Wii. $^{51}$

Various Wii related fractures have also been reported. A 38 year old man fractured his spinous C7 process after swinging a Wii remote vigorously, ${ }^{52}$ and a girl who fell during a game of Wii 
Fit sustained a small fracture of the fifth metatarsal of her right hand..$^{53}$ Another report described an intra-articular fracture of the first metacarpal bone in a patient who was playing a sports game. $^{54}$

Other injuries include a forehead laceration in a girl whose brother accidentally hit her with a Wii remote, ${ }^{55}$ and permanent loss of vision in a 7 year old boy after he accidentally struck his left eye while playing Wii Sports ${ }^{56}$ Finally, a woman experienced rupture of the extensor pollicis longus after hitting a wall while playing tennis. ${ }^{57}$

\section{Discussion}

Most reported problems related to use of the Nintendo are mild, and, given the number of gaming systems sold, the prevalence is low. The type of injury depends on the control system used. Excessive game play with traditional controllers is associated with tendinitis of the thumb; the Nintendo 64 joystick can lead to palmar ulceration; and the motion sensitive Wii remote can cause musculoskeletal problems and various traumas.

Nintendo has often acted on these problems-for example, the hand out of protective gloves ${ }^{33}$ and the massive give away of protective silicone covers for the Wii remote to prevent trauma (and smashed TV screens) ${ }^{58}$ These days Nintendo even warns players with in-game messages that remind them to take a break.

Overall, a Nintendo is a relatively safe Christmas present. However, those who receive such a gift should not swing the controller too hard, they should be careful about where they play, and they should take frequent breaks.

Contributors: MBJ conceived and designed the study and is guarantor. All authors helped interpret the data and draft the paper.

Funding: No funding was sought for this study. There were no study sponsors.

Competing interests: All authors have completed the ICMJE uniform disclosure form at www.icmje.org/coi_disclosure.pdf and declare: MBJ is an experienced gamer, a Nintendo collector, and a long term editor for the biggest video game websites in the Netherlands as well as several large children's magazines, for which he is paid; he also tests video games for Nintendo and other video game publishers and can keep the games afterwards; all other authors declare no support from any organisation for the submitted work; no financial relationships with any organisations that might have an interest in the submitted work in the previous three years; no other relationships or activities that could appear to have influenced the submitted work.

Ethical approval: Not required.

Data sharing: No additional data available.

Transparency declaration: The lead author (the guarantor) affirms that this manuscript is an honest, accurate, and transparent account of the study being reported; that no important aspects of the study have been omitted; and that any discrepancies from the study as planned (and, if relevant, registered) have been explained.

Nintendo. History of Nintendo worldwide 1889-1979. www.nintendo.co.uk/Corporate/ Nintendo-History/Nintendo-History-625945.html.

2 Nintendo. Consolidated sales transition by region. www.nintendo.co.jp/ir/library/historical data/pdf/consolidated sales e1406.pdf.

3 Chang WD, Chang WY, Lee CL, Feng CY. Validity and reliability of Wii Fit balance board for the assessment of balance of healthy young adults and the elderly. J Phys Ther Sci 2013;25:1251-3

4 Bieryla KA, Dold NM. Feasibility of Wii Fit training to improve clinical measures of balance in older adults. Clin Interv Aging 2013;8:775-81.

5 Brichetto G, Spallarossa P, de Carvalho ML, Battaglia MA. The effect of Nintendo Wii on balance in people with multiple sclerosis: a pilot randomized control study. Mult Scler 2013:19:1219-21.

6 Gonçalves GB. Using the Nintendo Wii Fit plus platform in the sensorimotor training of freezing of gait in Parkinson's disease. Arq Neuropsiquiatr 2013;71:828.

7 Mhatre PV, Vilares I, Stibb SM, Albert MV, Pickering L, Marciniak CM, et al. Wii Fit balance board playing improves balance and gait in Parkinson disease. PM R 2013:5:769-77.
8 Herz NB, Mehta SH, Sethi KD, Jackson P, Hall P, Morgan JC. Nintendo Wii rehabilitation ("Wii-hab") provides benefits in Parkinson's disease. Parkinsonism Relat Disord 2013:19:1039-42.

9 Jalink MB, Goris J, Heineman E, Pierie JPEN, ten Cate Hoedemaker HO. Construct and concurrent validity of a Nintendo Wii video game made for training basic laparoscopic skills. Surg Endosc 2014;28:537-42.

10 Bokhari R, Bollman-McGregor J, Kahoi K, Smith M, Feinstein A, Ferrara J. Design, development, and validation of a take-home simulator for fundamental laparoscopic skills: using Nintendo Wii for surgical training. Am Surg 2010;76:583-6.

11 O'Donovan C, Greally P, Canny G, McNally P, Hussey J. Active video games as an exercise tool for children with cystic fibrosis. J Cyst Fibros 2014;13:341-6.

12 Tripette J, Murakami H, Gando Y, Kawakami R, Sasaki A, Hanawa S, et al. Home-based active video games to promote weight loss during the postpartum period. Med Sci Sports Exerc 2014:46:472-8.

13 Staiano AE, Abraham AA, Calvert SL. Adolescent exergame play for weight loss and psychosocial improvement: a controlled physical activity intervention. Obesity (Silver Spring) 2013;21:598-601

14 Naugle K, Naugle K, Wikstrom E. Cardiovascular and affective outcomes of active gaming: using the Wii as a cardiovascular training tool. J Strength Cond Res 2014;28:443-51.

15 Puh U, Majcen N, Hlebš S, Rugelj D. Effects of Wii balance board exercises on balance after posterior cruciate ligament reconstruction. Knee Surg Sports Traumatol Arthrosc 2014;22:1124-30

16 Sparks DA, Coughlin LM, Chase DM. Did too much Wii cause your patient's injury? J Fam Pract 2011;60:404-9.

17 George AJ. Musculo - ske Wii tal medicine. Injury 2012;43:390-1.

18 Fysh T, Thompson JF. A Wii problem. J R Soc Med 2009;102:502.

19 Hart EJ. Nintendo epilepsy. N Engl J Med 1990:322:1473.

20 Kasteleijn-Nolst Trenité DG, da Silva AM, Ricci S, Binnie CD, Rubboli G, Tassinari CA, et al. Video-game epilepsy: a European study. Epilepsia 1999;40(suppl 4):70-4.

21 Corkery JC. Nintendo power. Am J Dis Child 1990;144:959.

22 Schink JC. Nintendo enuresis. Am J Dis Child 1991;145:1094.

23 Miller DL. Nintendo neck. CMAJ 1991;145:1202.

24 Bright DA, Bringhurst DC. Nintendo elbow. West J Med 1992:156:667-8.

25 Spence SA. Nintendo hallucinations: a new phenomenological entity. Irish J Psychol Med 1993;10:98-9

26 Brasington R. Nintendinitis. N Engl J Med 1990;322:1473-4.

27 Casanova J. "Nintendinitis." J Hand Surg Am 1991;16:181.

28 Siegel IM. "Nintendonitis." Orthopedics 1991:14:745.

29 Macgregor DM. Nintendonitis? A case report of repetitive strain injury in a child as a result of playing computer games. Scott Med J 2000;45:150.

30 Schnicke M. Atopischer Daumen. Pilzerkrankung? Nein, der Gameboy ist schuld! MMW Fortschr Med 2011;153:5.

31 Koh TH. Ulcerative "nintendinitis": a new kind of repetitive strain injury. Med J Aust 2000;173:671.

32 Wood DJ. The "How!" sign - a central palmar blister induced by overplaying on a Nintendo console. Arch Dis Child 2001;84:288.

33 Nintendo to hand out gaming gloves. BBC News 2000. http://news.bbc.co.uk/2/hi/science/ nature/671601.stm.

34 Jones C, Hammig B. Case report: injuries associated with interactive game consoles: preliminary data. Phys Sportsmed 2009;37:138-40.

35 Sparks D, Chase D, Coughlin L. Wii have a problem: a review of self-reported Wii related injuries. Inform Prim Care 2009;17:55-7.

36 Bonis J. Acute Wiiitis. N Engl J Med 2007;356:2431-2.

37 Cowley AD, Minnaar G. New generation computer games: watch out for Wii shoulder BMJ 2008;336:110.

38 Harrison M. No Wii cause for concern. Emerg Med J 2009;26:150.

39 Baxter RD, Madhok RM. A case of arm swelling and muscle Wii-kness. Scott Med J 2011:56:236.

40 Nett MP, Collins MS, Sperling JW. Magnetic resonance imaging of acute "wiiitis" of the upper extremity. Skeletal Radiol 2008;37:481-3.

41 Rubin D. Triad of spinal pain, spinal joint dysfunction, and extremity pain in 4 pediatric cases of "Wii-itis": a 21st century pediatric condition. J Chiropr Med 2010;9:84-9.

42 Boehm KM, Pugh A. A new variant of Wiiitis. J Emerg Med 2009:36:80.

43 Beddy P, Dunne R, de Blacam C. Achilles wiiitis. AJR Am J Roentgenol 2009;192:W79.

44 Singh R, Manoharan G, Moores TS, Patel A. Nintendo Wii related Achilles tendon rupture: first reported case and literature review of motion sensing video game injuries. BMJ Case Rep 2014; doi:10.1136/bcr-2013-202657.

45 Brodmann M, Gary T, Hafner F, Eller P, Deutschmann H, Pilger E, et al. Acute wiiitis representing as thrombosis of the inferior vena cava and left pelvic veins. Phlebology 2014; published online 28 Mar.

46 Hirpara KM, Abouazza OA. The "Wii knee": a case of patellar dislocation secondary to computer video games. Injury Extra 2008;3:86-7.

47 Robinson RJ, Barron DA, Grainger AJ, Venkatesh R. Wii knee. Emerg Radio 2008;15:255-7.

48 Almedghio SM, Shablahidis O, Rennie W, Ashford RU. Wii knee revisited: meniscal injury from 10-pin bowling. BMJ Case Rep 2009; doi:10.1136/bcr.11.2008.1189.

49 Peek AC, Ibrahim T, Abunasra H, Waller D, Natarajan R. White-out from a Wii: traumatic haemothorax sustained playing Nintendo Wii. Ann R Coll Surg Engl 2008;90:W9-10.

50 Khan OA, Parvaiz AC, Vassallo DJ. Acute hernial strangulation following Wii Fit exercises. Acta Chir Belg 2013;113:58-9.

51 Faivre A, Chapon F, Combaz X, Nicoli F. Internal carotid artery dissection occurring during intensive practice with Wii video sports games. Neurology 2009;73:1242-3.

52 Brown CN, McKenna P. A Wii-related clay-shoveler's fracture. Scientific World Journal 2009;9:1190-1.

53 Eley KA. A Wii fracture. N Engl J Med 2010;362:473-4.

54 Galanopoulos I, Garlapati AK, Ashwood N, Kitsis C. A Wii virtual activity severe thumb metacarpal injury. BMJ Case Rep 2012; doi:10.1136/bcr-2012-006967.

55 Wells JJ. An 8-year-old girl presented to the ER after accidentally being hit by a Wii remote control swung by her brother. J Trauma 2008;65:1203.

56 Razavi H, Lam G. Wii eye injury: self-inflicted globe rupture and vision loss in a 7-year-old boy from a video game accident. J AAPOS 2011;15:491-2.

57 Bhangu A, Lwin M, Dias R. Wimbledon or bust: Nintendo Wii related rupture of the extensor pollicis longus tendon. J Hand Surg Eur Vol 2009;34:399-400.

58 Nintendo. Wii remote jacket accessory offer. www.nintendo.com/consumer/jacket/ jacketrequest.jsp. 


\section{Summary points}

Nintendo related injuries and other problems have been reported for all types of video game consoles

The injury depends on the way the game is controlled.

Traditional wired controllers are associated with tendinitis of the thumb

Motion sensitive Wii remote controllers can give rise to (upper extremity) musculoskeletal problems and various traumas

Nintendo is relatively safe if the player takes frequent breaks and plays in a safe place

\section{Accepted: 6 October 2014}

Cite this as: $B M J$ 2014;349:97267
This is an Open Access article distributed in accordance with the Creative Commons Attribution Non Commercial (CC BY-NC 4.0) license, which permits others to distribute, remix, adapt, build upon this work non-commercially, and license their derivative works on different terms, provided the original work is properly cited and the use is non-commercial. See: http://creativecommons.org/licenses/by-nc/4.0/. 